Circumference of chest over the tumours, thirty-eight inches; slight cuticular discoloration of the left.

After admission the left tumour slowly and steadily increased in size, fluctuation and dilatation becoming more distinct, and the right tumour becoming merged in it. The discoloration increased and decreased, but soon became permanent at the left apex, which was now evidently becoming thinner. Treatment by iron, sedatives (of which chloral and aconite proved the most useful by alleviating pain), and iodide of potassium, in large doses, pushed to iodism.

On the 23rd March, a fatal issue evidently approaching, fourteen inches of fine wire was passed through a long. canula of one-sixteenth of an inch diameter into the left tumour from the left side, the wire being passed until resistance was experienced. The canula appeared to move freely in the sac, and only a few drops of black treacly blood escaped. This operation at first appeared to have a beneficial effect, the tumours decidedly becoming firmer and the impulse and discoloration less; but on the $28 \mathrm{th}$ March the bulging again increased, until, by the 9th April, it was almost nipple-like, the skin thin and black, and rupture imminent. The respiration on the left side also became feeble, and at times almost deficient. Nine fine needles, two and a half inches long, were then passed into the tumour at different points of the circumference, their points being directed so as to cross one another about an inch and a balf below the prominent point. No pain was experienced in passing them, and no blood was lost. On the 11th of April blood began to ooze in drops, at first from the apex. On the 14th, six or eight ounces of blood escaped from it and the wire wound; and on the 16th a further free bæmorrhage. A closely fitting guttapercha shield was then secured to the chest, with the idea of prolonging life by forming an external and possibly internal coagulum. This shield had a piece of glass let into the top, and a couple of gutta.percha tubes in order to inject if necessary. On the 20 th free hæmorrhage recurred; and on the 23rd, when he was evidently sinking, there was a final profuse bleeding, which forced up the case, and he sank in ten minutes.

On post-mortem examination, a fungous, fibrinous coagulum was found extruding from the apex of the tumour, which had completely given way; and on opening the thorax an enormous fusiform dilatation of the aorta, extending from above the a,ortic valves, which were healthy, to an inch beyond the left subclavian, the aneurism at its greatest point of dilatation having a circumference of eight inches. About two inches from the valves in the anterior wall of the aorta was a large orifice of the size of a half-crown, by which communication was kept up with a sacculated aneurism, of the size of a large orange, lying in the anterior mediastinum between the sternum and the heart, lined with thick, partly organised layers of fibrine. In the sternum, implicating chiefly the left side, was a circular eroded opening, having rough edges, of the size of a florin; and externally, forming the visible tumour, a small sac, of the size of an egg, with organised lining membrane, surrounded by dark fibrinous coagulum, of from threeguarters of an inch to one inch in thickness. The sac was ruptured, there being an opening of the size of a shilling, by which the fatal hæmorrbage had taken place. In the coagulum, embedded in its lower border, was found the wire, coiled up irregularly in the form of a figure of 8 . The wire and needles were only partly oxidised. The lungs were healthy, with the exception of a portion of the left lower lobe, which was hepatised. The pericardium was loaded with fat, and adherent throughout to the heart; and there was some serous effusion into the left pleural cavity.

Ovariotomy in Paris.-M. Panas has communicated to the Surgical Society of Paris (July 26th, 1871) the socount of an operation of this kind. Both ovaries were diseased, the cysts were multilocular and contained much eolloid matter. A clamp was used on the right side but not on the left. The patient died of peritonitis.

The Franco-German conflict has deprived 101 German military medical officers of life-6 died on the field of battle, 66 after gnnshot wounds, 2 were accidentally killed, 25 died of disease, and 2 met their death in consequence of imprudence.
STENOSIS OF THE PULMONARY ARTERY, FROM ENDOCARDITIS IN FETAL STAGE, INCREASED BY ENDOCARDITIS AFTER PUBERTY ; DEATH BY PHTHISIS.

BY DR. W. R. E. SMART, C.B., R.N., INSPBCTOR-GENERAL OF HOSPITALS.

INTEREST in this cardiac malformation has been lately renewed by the views of Lebert, in confirmation of which a case of the myocarditic variety, by Dr. Dyce Brown, has appeared in THE LANCET. As the following case of the endocarditic variety possesses peculiar features, it is offered to increase the scanty records of a malady as remarkable in its physiological as in its pathological relations.

J. C- was admitted to Greenwich Hospital from Haslar, with incurable heart disease, and died there on Nov. 5 th, 1868 , aged eighteen years.

His parents were unknown to him; he believed they died young; and he was brought up at a public institution. He was examined physically before entry in the navy, in October, 1865 (aged fifteen), when no abnormality or disease was detected. He was sent to a training ship, where he was drilled and exercised aloft and in boats. Ten months after entry he was discharged to Haslar, with "disease of the heart and rectal abscess." While there the lad had several attacks of hrmoptysis, in one of which he lost at least a quart of blond. This happened on the $28 \mathrm{th}$ of July, 1867 , and he was discharged to Greenwich on the 21st of August following.

On admission there the patient's disease was classed "beart disease and phtbisis." He was slight and ill-developed; his features were thin and pallid; lips and ends of fingers cyanosed by exertion; pulse 112, small and weak, but regular; respiration 28, and shallow; dyspncea on exertion; no hectic; digestive powers unimpaired. A harsh systolic murmur was beard over the arterial orifices, extending along the track of the great vessels, and very distinctly over two inches around the third dorsal spine. It was hissing, and loud enough to musk the first sound, conceal the second, and obscure those of respiration. A cavern was deterted under the left clavicle, and the murmur was intensified by passing through it.

During the after-progress be had repeated attacks of copious spitting of clotted and florid blood, but in the intervals of these he was cheerful and even playful, although fits of coughing and dyspnosa were brought on by exertion or laughter. His appetite remained unimpaired, and between Feb. 1st and Aug. 1st, 1868, his weight stood at $93 \mathrm{lb}$. His strength then began to fail, hectic appeared, and in August he lost $2 \frac{1}{2} \mathrm{lb}$. weight, and as much in September, after which he emaciated rapidly; in September he bad melæna, and early in October he took to his bed. The phthisical signs advanced quickly at both apices; dyspnoa became urgent, and when abont to speals he took forced inspiration; lividity of the lips, ears, and tips of fingers was nearly persistent; the cardiac murmur, approaching to whistling, concealed every other sound, and was very distinctly heard at five inches from the ear-piece of the stethnscope resting over the upper cardiac region. Throughout October his cardiac anxiety and dyspnœa. were distress. ing, and hectic with rignrs and profuse perspirations left him but little repose. During the last two weeks of life he had continuous hæmoptysis in purulent sputa; his feet became codematous and extremely tender, and abrasions formed over the sacrum. He expired, as before stated, on the 5th of November, 1868, three years after entering the naval service.

Sectio cadaveris, fifty-six hours after death, by AssistantSurgeon $\mathrm{P}$. Keelan, in my presence.-Brdy much emaciated and exsanguined, weighing $72 \mathrm{lb}$.- Head not examined. Both lungs closely adberent to parietes, indurated with miliary tuhercles, and having in each apex a cavern, that in the left being lined with a villous leathery membrane pierced by patent bronchi, and that in the right with a soft gelatinous laver. The heart weighed $11 \mathrm{oz}$, it was of conical shape, and the pericardium was normal. On looking down the truncated aorta, its valves were seen to be normal; but on looking into the pulmonary artery, it was 
seen to be a tube of at least full calibre, nearly closed below by a vaulted curtain formed by agglutination of the margins of the sigmoid valves, leaving a chink only between two of the segments, the borders of this chink being nodulated and indurated by cretaceous deposit, and the rima filled by an atheromatous, pea-like body that was attached by a pedicle to the ventricular surface of the valve. It was difficult to conceive how any current of blood could have passed through it from the ventricle into the pulmonary artery. On laying open the heart, the auricles were seen to be much dilated and almost diaphanous between the muscular bands, their septum being in the same state, but complete; the ventricular walls were red and firm in structure and of equal thickness, and the cavities were of equal capacity; the septum of the ventricles was incomplete at its upper part, admitting a finger freely into the aorta from the cavity of the right ventricle. Both auriculo-ventricular valves were incompetent; the mitral had one wide and one narrow flap; the tricuspid was narrow, and its curtains indurated and nodulated at their commissures. A very remarkable conformation was noticed at the free borders of those two curtains whose commissures lay towards the septum; they were expanded in two wings angularly to the ventricular surface of the valve. These wings were not indurated like the valve itself, and they bore an evident relation to the opening in the septum. So long as a current was maintained in the pulmonary artery they would serve in some degree to obstruct the false orifice, but without that current their action must have been diastolic as well as systolic. During the ventricular diastole they occluded the false orifice and directed the current into the apex of the right ventricle; but during the systole they served to fortify the tricuspid at the weak point opposite to that orifice, and to prevent the forcible regurgitation of blood into the right auricle during the combined ventricular stroke. A preparation of the heart was set up.

The definition of the malformation was the double auricle and single ventricle type of the amphibia, modified by a partition in the ventricle and by a supplemental valve which lay in front of the abnormal orifice.

Life was possible so long as the stenosis did not interfere in high degree with the pulmonary circulation, but as soon as the late attack of endocarditis, brought on by the new cardiac requirements of "training," had increased the obstruction to it, a fatal course was instituted in the lungs. Latterly, the bronchial arteries, which were large, were the chief propelling agents of the pulmonary circulation, as the stenosis and the very wide vessel beyond it counteracted the force of the right ventricle in that direction.

The liver, spleen, and kidneys were all of large size and highly congested, while the exterior tissues were greatly exsanguined. The accepted dogma, that venosity of the blood is opposed to the development of tubercle, receives, it appears to me, some degree of contravention in the uniform result of these cases of pulmonary stenosis.

South Penge Park, S.E., August, 1871.

REPORT ON A CASE OF

\section{REMOVAL OF A PORTION OF BONE FROM THE RECTAL FOSSA.}

By JAMES THOMPSON, M.D., M.R.C.P., M.R.C.S.

Mr. M-, aged seventy-in early life an active man, walking many miles daily,-twenty years since began to suffer from pains in the back and pelvis, which obliged him to give up horse exercise, and he could walk only short distances. He suffered in this way for five years before he consulted his surgeon, who, after an examination, told him there was no local cause for his suffering, and prescribed leeches and aperients, with benefit for a time. One of his friends then told him that it must be piles be suffered from, and recommended him to take milk of sulphur, as "it had cured him." He took some with relief, and since then for. about fourteen years has taken some almost every day.

In November last he came under my care. He was then a stout, healthy-looking man, of full habit of body, and complained of tympanites, nausea, tenderness over the ab- domen, scanty high-coloured urine, and slightfever; bowels costive. He said he had piles, but would not permit any examination of them, as he did not think his present symptoms were caused by them. Diaphoretics and diuretics were prescribed, and in a few days he declared himself convalescent. A few days after I found him in the same state, but with gout in the right great toe. Alkalies and a more generous diet in a few days relieved the gout, but the general state remained much the same.

I felt sure the so-called piles were the cause of the disturbance. I insisted on a consultation, and arranged to see him with Dr. Slack, of this town. We found an almost raw surface, extending two inches round the anus, and a zone of erysipelatous blush four inches in breadth. On the left side, about an inch from the anus, there was a small opening, through which appeared a small black point. 'This was seized and drawn out by slightly enlarging the orifice, and proved to be a piece of bone three-quarters of an inch square. No piles were found. A probe passed through the external opening entered the rectum a short distance above the sphincter, and a considerable cavity remained where the bone had rested. The following day two other small pieces of bone were removed. The sore was dressed with a carbolic-acid lotion, and when the inflammatory state had passed away the now fistula was laid open, and in a few days the wound healed up, and his general health improved greatly. He declared that he now felt more comfortable than he had done for twenty years. Since that time he has regained much of his former activity, and is now in excellent health.

The pieces of bone were examined, and were possibly portions of the scapula of a rabbit. The patient thinks "it has been in him all these years"; if so, it must have lodged in some portion of the intestine, ulcerated its way out, and gradually reached the pelvic opening. There is no history of any injury to the spine or sacrum.

The quantity of sulphur taken was enormous-half a teaspoonful almost every day. He states that it gave him temporary relief. It may have acted by relieving the rectum, and so removing pressure of its walls against the bone, and possibly the more sensitive parts of the walls of the pelvic cavity.

Leamington, June, 1871.

\section{TWO CASES OF SUNSTROKE.}

BY J. W. MACDONALD, M.B., T.R.C.S.E.

CASE 1.-W.S_, aged sixty-three, a farm-labourer, was at work in a turnip-field on August 11th. He could take no dinner, and had complained much of the heat on the two preceding days. At 6 P.M. he returned from the field, and, while removing the harness from a horse, suddenly dropped down in an unconscious state.

I saw him half an hour afterwards. He was in a sitting posture, propped up by pillows, breathing loudly and moaning; there was slight stertor; the skin was hot and moist. He could not be roused. The pulse beat 140 per minute, full and strong; there was a marked throbbing of the carotid and temporal arteries. The pupils were contracted slightly and insensible to light.

I immediately had the patient placed in the recumbent posture; the head was raised and cold applied to it, while sinapisms were applied to the extremities. The symptoms continuing, I about ten minutes afterwards drew twelve ounces of blood from the arm. The pulse immediately became slower and softer, but he gradually sank. Death took place an hour and a half from the beginning of the attack.

The propriety of bloodletting in cases of insolation is doubted by many. The conditions which induced me to resort to it were, the strength and fulness of the pulse, the heat of the surface of the body, and the throbbing of the carotid and temporal arteries.

CASE 2. - J. R-, aged thirty-four, immediately after taking a full meal, at which he drank water very freely, walked into the open air with his head uncovered. He suddenly fell down, and was carried into his house in an insensible state.

I saw him immediately. The symptoms all indicated exhaustion. He rallied in a few minutes and became quite 